NASA Technical Memorandum 100238

\title{
Free-Edge Delamination: Laminate Width and Loading Conditions Effects
}

P.L.N. Murthy and C.C. Chamis

Lewis Research Center

Cleveland, Ohio

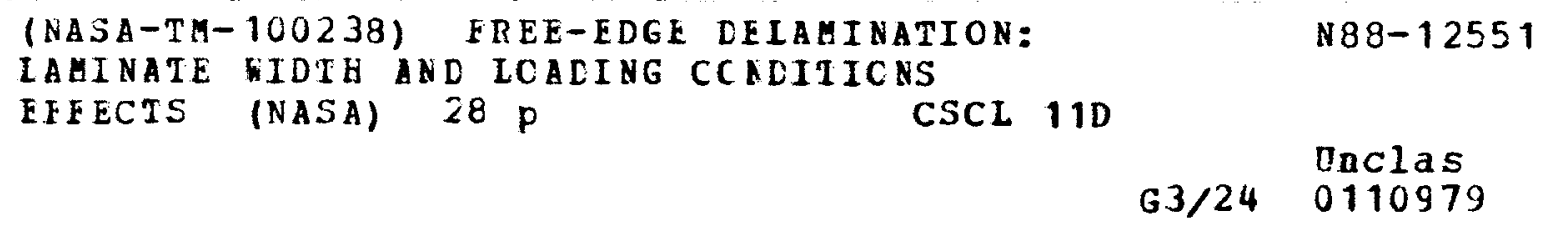

December 1987

\section{N/SA}


FREE-EDGE DELAMINATION: LAMINATE WIDTH AND LOADING CONDITIONS EFFECTS

\author{
P.L.N. Murthy* and C.C. Chamis \\ National Aeronautics and Space Administration \\ Lewis Research Center \\ Cleveland, Ohio 44135
}

\begin{abstract}
SUMMARY
The width and loading conditions effects on free-edge stress fields in composite laminates are investigated by using a three-dimensional finite element analysis. The analysis includes a special free-edge region refinement or superelement with progressive substructuring (mesh refinement) and finite thickness interply layers. The different loading conditions include in-plane and out-of-plane bending, combined axial tension and in-plane shear, twisting, uniform temperature and uniform moisture. Results obtained indicate that: axial tension causes the smallest magnitude of interlaminar free edge stress compared to other loading conditions, free-edge delamination data obtained from laboratory specimens can not be scaled to structural components, and composite structural components are not likely to delaminate.
\end{abstract}

\title{
INTRODUCTION
}

Free-edge stress fields and delamination in composite laminates has been (Ref. 1) and continues to be (Refs. 2, 3, and 4) an active research activity in the composite community. In previous studies (Ref. 1) the authors provided a selective summary of the literature to that date and presented the results of their studies on the effects of the interply layer on the free-edge stress fields. These effects were investigated by modeling the entire laminate geometry using three-dimensional finite elements with special free-edge region refinement or superelements. The interply layers were modeled as

\footnotetext{
${ }^{*}$ Cleveland State University, Cleveland, Ohio 44115; NASA Senior Resident Research Associate.
} 
individual layers with thickness dimensions which were predicted by composite micromechanics for particular fiber volume ratios. The study was mainly limited to one specimen geometry under axial tension. Results from that study indicated that: (1) the inclusion of an interply layer affects the magnitude and sense of the interlaminar stress near the free-edge, (2) modeling the entire specimen influenced the behavior of the in-plane ply stress near the free edge and (3) substantial in-plane stresses were present in the interply layer. It became apparent, therefore, that specimen geometry and different loading conditions will also affect the free-edge stress field in composite laminates.

The objective of the present study, described herein, was to investigate the width-to-thickness ratio and loading condition effects on the free-edge stress fields in angleplied laminates (APL). Specifically, the following cases were investigated: (1) ply angle effects on axial stress, (2) width/thickness ratio effects, (3) axial tension (reference case), (4) in-plane shear, (5) out-of-plane shear/bending, (6) in-plane bending, (7) twisting moment, (8) combined loading, (9) uniform thermal load and, (10) uniform moisture load. Comparisons for the various loading conditions are also included.

The reasons for selecting each case are described in detail in terms of the relative importance and significance of the results obtained to composite structural components. The computational simulation was described in Ref. 1 and is briefly summarized here in for completeness.

\section{COMPONENT GEOMETRY AND FINITE ELEMENT MODEL}

The component geometry is a flat plate as shown schematically in

Fig. 1. The plate is made from a four ply symmetric and balanced $[ \pm \theta]_{\mathrm{s}}$ angleplied laminate. The finite element model and the structural coordinate axes are shown in Fig. 2. This figure depicts the finite element model when 
it is loaded in tension at one end and fixed at the other. Analogous conditions were used for the other cases as is described later.

The finite element model consists of a uniform mesh of 20-node solid finite elements (F.E.) and one free edge superelement with 224 finite elements. Each ply and each interply layer are modeled with one element through the thickness. The model consists of 7561 nodes with three displacements per node $(u, v, w)$ or a total of 22683 degrees of freedom (D.O.F.). The free edge superelement region with its respective progressive mesh refinement (substructuring) is shown in Fig. 3. The plane dimension of the smallest element in the superelement region are 1/256 in. The free edge stresses are calculated at the center of this element or $(1 / 512)$ in. from the free edge.

The composite component is assumed to be made from an AS-graphite fiber/epoxy (AS/E) composite with 0.55 fiber volume ratio. The ply properties (unidirectional composite) used in the finite element analysis were generated with ICAN (Ref. 5) and are typical for this composite system. The interply layer is assumed to consist of only matrix (Fig. 4) and, therefore, has the same properties as the epoxy in the plies. The properties for both the ply and the interply layer are summarized in Fig. 5 where the schematic depicts the material axes $(1,2,3)$ along which the material properties are defined. The notation in Fig. 5 is the same as that used in MSC/NASTRAN and was adopted for convenience.

The specific angleplied laminate configurations considered were $[ \pm \theta]_{2} \mathrm{~s}$ $(\theta=10,20,30,40,45,50,60,70,80$ and 90 degrees $)$. The finite element consisted of 7 solid elements through-the-thickness: 3 for the interply layers and four for the plies. The ply orientation angle $\theta$ (from the structural $x$-axis to the material l-axis) was inputted in order to invoke the NASTRAN option for property transformation. 
CASES STUDIED AND RESULTS OBTAINED

The various cases studied are summarized in Fig. 6. A brief discussion for selecting these cases, results obtained, and significance of these results follows.

\section{CASE 1. Ply Angle Effects on Axial Stress}

It is normally assumed in free-edge interlaminar stress studies that either the axial strain or axial stress are constant across the specimen width when the specimen is subjected to axial tension. Therefore, this case was selected to study the axial stress variation at the free edge as a function of the ply angle under constant tensile load. The results obtained from this case $\left(\sigma_{X X}\right)$ are normalized with respect to the far field stress $\left(\sigma_{X X^{\infty}}\right)$ and are shown in Fig. 7. If $\sigma_{x x}$ remained constant across the width then $\sigma_{x x} / \sigma_{x x}$ should be about 1 for all $\pm \theta$ laminates. However, in Fig. 7 , this is only true for $\pm \theta$ laminates in the $50^{\circ} \leq \pm \theta \leq 80^{\circ}$ range. Therefore, the conclusion is that $\sigma_{x x}$ is not constant across the width except for a very small range of $\pm \theta$ ply orientations. Furthermore the variation shown in Fig. 7 will more than likely depend on width and on composite material system. The practical implication is that evaluation of free-edge interlaminar stress magnitudes and possible delaminations must be based on analysis models and/or experiments using representative component geometries and loading conditions. Otherwise the results obtained are only indicative of the specific case studied and any inference or extrapolation to a different case may be misleading.

CASE 2. Width/Thickness Ratio Effects

The study of the width-to-thickness ratio effects on free-edge interlaminar stress is motivated by the observations that laboratory specimens loaded in tension/compression exhibit free-edge delamination while both simulated and actual components do not. Laboratory specimens are relatively narrow (about or less than one inch) while simulated and/or actual components 
are not. One explanation may be possible width/thickness (W/T) ratio effects on these stresses. The studies for this case were performed to simulate the W/T ratio effects on the interlaminar normal $\left(\sigma_{z Z}\right)$ and shear $\left(\sigma_{X z}\right)$ stresses. Typical results obtained are shown in $\mathrm{Fig}$. 8 . The results are for $\mathrm{a}[ \pm 45]_{S}$ angleplied laminate which had the highest magnitude of interlaminar stresses near the free edge.

The significant observations in Fig. 8 are: (1) The interlaminar stresses $\sigma_{Z z}$ and $\sigma x z$ are very sensitive to small W/T ratios (less than 4 ). (2) The magnitude of $\sigma_{z z}$ becomes negligible with $W / T$ ratios greater than 30 while $\sigma_{x z}$ remains practically constant. (3) The magnitude of $\sigma_{z z}$ is initially compressive, reaches its peak tensile value at a W/T ratio of about 4 and decreases rapidly thereafter. The magnitude of the $\sigma_{x z}$ stress increases very rapidly in this lower range $W / T$ ratio.

It is worth noting that the analytical results and, therefore, conclusions in the literature are for specimens with W/T ratios of about 8 . The corresponding experimental data is from specimens with W/T ratio of about 16. Clearly $\sigma_{z z}$ has substantial magnitude in this range and will contribute significantly to free edge delamination. This contribution becomes even more critical considering that the through-the-thickness tensile strength is relatively smaller than the intralaminar shear strength. The authors consider the results in Fig. 8 as evidence/explanation why laboratory specimens delaminate while simulated and/or actual components do not. The practical implication of the results from this case is that edge delamination is not likely to occur in composite structural components assuming normal design and manufacturing practices.

The triaxial stress field near the free edge is shown in Fig. 9 (Ref. 1) where each stress magnitude is plotted versus the free edge length parameter $x_{r}$ measured from inner edge ( $1 \mathrm{in}$. from the free-edge) of the superelement 
(Fig. 3). The nearest point to the free edge, at which stresses are plotted, is $1 / 512$ in. As can be seen, the stresses in both the ply and the interply layer are plotted. The interesting points to observe are: (1) the interlaminar stresses $\left(\sigma_{z z}, \sigma_{z y}, \sigma_{x z}\right)$ have significant magnitudes near the free edge. The inplane stresses $\left(\sigma_{x x}, \sigma_{x y}\right)$ in the plies decrease rapidly as the free edge is approached while oyy exhibits oscillatory behavior. The inplane stresses $\sigma_{x x}$ and $\sigma_{x y}$ in the interply layer are negligible and near zero except $\sigma_{y y}$. This stress is primarily caused by the mismatch in the Poisson's ratio between the plies and the matrix. The important point to be noted from the above discussion is that local mesh refinement or the superelement are effective means to determine the three-dimensional stress field near free edges. These results indicate that both interlaminar stresses $\sigma_{Z z}$ and $\sigma_{X z}$ are of about the same magnitude (about 1 to 2 percent of $\sigma_{X x}$ ) while $\sigma_{z y}$ is an order of magnitude less as the free-edge is approached.

CASE 3. Axial Tension - Reference Case

Interlaminar stresses near the free edges in axial tensile flat specimens (Fig. 6) have been and continue to be extensively studied (Refs. 1 , 2 and 3 ). One of the major reasons is the specimen's simplicity for experimental studies. For example, the edges can be continuously monitored for the onset of transpiy cracks and delaminations during monotonic and/or cyclic loading. The other reason is the large number of available theoretical solutions, as was already mentioned.

The three-dimensional stress field near the free edge of an axially loaded tensile specimen is presented in Fig. 9 (Ref. 1). This is used as a reference case in order to compare the corresponding stress fields from the other loading conditions. The stress field in this figure is for a $[ \pm 10]_{S}$ AS/E APL because previous studies (Ref. 1) indicated that the interlaminar normal stress $\sigma_{z z}$ was more likely to initiate edge delamination in this APL. 
The important points to observe in Fig. 9 and to keep in mind for subsequent comparisons are: (1) the magnitudes of the two interlaminar stresses, $\sigma_{z z}$ and $\sigma_{z x}$, and (2) the general behavior of the inplane stresses, $\sigma_{x x}$ and $\sigma_{y y}$. It is also important to note that the free stress surface at the edge requires that the interlaminar stress $\sigma_{z y}$ and the inplane stresses $\sigma_{x y}$ and $\sigma_{y y}$ vanish at the free edge. This is not obvious in Fig. 9 since the last point in the stress field is at the centroid of the edge finite element which is $1 / 512$ in from the free edge as was already mentioned.

CASE 4. In-PIane Shear

The free-edge stress field in APL subjected to in-plane shear (Fig. 6) has not been previously investigated. In-plane shear is the dominant loading condition in skin-stringer and shear-web structural components. Since these types of components generally have free edges it is appropriate to determine the three-dimensional free-edge stress field and compare the magnitudes of its respective stresses to those of the axial tension. As far as the authors know, no incidents of free-edge delaminations have been reported for these types of structural components.

The normalized (with respect to corresponding $\sigma_{x x}$ ) free-edge three-dimensional stress field in a $[ \pm 10]_{S}$ AS/E APL is shown in Fig. 10. Several points are worth noting: (1) the interlaminar stresses $\left(\sigma_{z z}, \sigma_{z y}\right.$ and $\left.\sigma_{x z}\right)$ in the interply layer have greater magnitudes than the corresponding ply stresses; (2) the interlaminar stress $\sigma_{z z}$ is compressive; (3) the interlaminar stress $\sigma_{y z}$ has substantial magnitude compared to the axial tension case (Fig. 9); (4) the in-plane stresses $\sigma_{x x}$ and $\sigma_{x y}$ have similar behavior as those for the axial tension case (Fig. 9); and (5) the ply stress oyy changes from compression to tension inwards from the free-edge while that for the axial tension case remains compressive (Fig. 9). 
The conclusion from the above discussion is that the three-dimensional stress field near the free-edge of APL subjected to in-plane shear is generally the same as that for the axial tension case except for the interlaminar normal stress $\left(\sigma_{z z}\right)$ which is compressive. This may explain, in-part, why free-edge delaminations have not been reported/observed in skin-stringer and shear-web type composite structural components, and it is consistent with the prevalent contention that "the interlaminar normal tensile stresses initiate free-edge delaminations".

CASE 5. Out-of-Plane Shear/Bending

Through-the-thickness shear stress $\left(\sigma_{x z}\right)$ is present in: (1) all structural components subjected to bending, (2) thickness transition regions, (3) normal to the laminate plane load application points and (4) joints. Through-the-thickness shear is simulated using a cantilever with an out-of-plane end load (Fig. 6). The three-dimensional stress field near the free-edge in APL due to this type of loading has not been investigated previously to the authors' knowledge. Experimental results indicating free-edge delaminations from this type of loading have not been reported in the literature for either laboratory specimens or structural components.

The normalized (with respect to corresponding $\sigma_{x x}$ ) three-dimensional stress field near the free-edge in $a[ \pm 10]_{S}$ AS/E APL is shown in Fig. 11 . Through-the-thickness shear induces interlaminar stresses $\left(\sigma_{z z}\right.$ and $\left.\sigma_{x z}\right)$ which are about an order of magnitude greater compared to the axial tension case. This of course should be expected since this type of loading directly subjects the laminate to interlaminar stresses. Even the interlaminar stress $\sigma_{z y}$ reaches comparatively high magnitudes just before the free-edge. The behavior for the in-plane stresses is the same in magnitude as that for the axial tension. The sign depends on the location of the interply/ply of interest relative to the mid-plane. 
The relevant conclusion from the above discussion is that out-of-plane loads induce relatively high interlaminar normal and shear stresses near free-edges of APL. Therefore, it is very important that regions subjected to these types of stresses are properly designed and validated using three-dimensional analysis.

\section{CASE 6. In-plane Bending}

In-plane bending is perhaps the most prevalent loading condition in the faces of sandwiches and in covers/sides/bulkheads of thin-wall, built-up structures. Since these structures will generally have free edges, the three-dimensional stress field near free-edges of composite APL subjected to in-plane bending is of interest. Neither free-edge delaminations in this situation nor analytical studies to evaluate the magnitudes of the corresponding interlaminar stresses have been reported.

In-plane bending is computationally simulated as shown in Fig. 6 . The normalized (with respect to corresponding $\sigma_{\mathrm{Xx}}$ ) three-dimensional stress field near the free-edge of a $[ \pm 10]_{S}$ AS/E APL is shown in Fig. 12. The interlaminar stresses due to in-plane bending exhibit the same behavior as for axial tension (Fig. 9) but of about twice the magnitude. The in-plane stresses on the other hand are practically identical.

The relative magnitudes of the interlaminar stresses for in-plane bending and axial tension lead to the conclusion that: Free-edges in the faces of composite sandwiches and in the composite members of thin-wall structures are more likely to delaminate when subjected to in-plane bending than to comparable far-field stress due to axial tension. Since no free-edge delaminations in such structural components have been reported, the practical implication is that free-edge delaminations do not occur in composite structural components/structures when they are designed and fabricated according to acceptable engineering practices. It is important that the 
free-edge delaminations, discussed here, are those within the APL and not between faces and core or in the adhesive which bonds the composite panels in built-up thin-wall structures.

\section{CASE 7. Twisting Moment}

Out-of-plane twisting moment (Fig. 6) is another prevalent loading condition in the faces of composite sandwiches or in the skins of skin-stringer structures. Free edges in such structures are common unless specifically protected by design. No delaminations have been reported in composite structural components from this type of loading as was the situation for Case 6. Likewise, computational simulation studies for this type of loading have not been reported.

The three-dimensional stress field near free edges is determined herein using a cantilever subjected to a free-end twisting moment as shown in Fig. 6. The normalized (with respect to corresponding $\sigma_{X X}$ (predicted using laminate theory)) three-dimensional stress field near the free-edge in a $[ \pm 10]_{S}$ AS/E APL is shown in Fig. 13. The interlaminar stresses have higher magnitudes compared to those for the axial tension case (Fig. 9). The behavior and magnitudes of the in-plane stresses $\sigma_{x x}$, $\sigma_{y y}$ and $\sigma_{x y}$ differ significantly from the axial tension case as well as from all previous cases.

The practical implication of the results in Fig. 13 is that a composite structural component with a relatively high aspect ratio and subjected to twisting may be prone to free-edge delamination. Examples of these types of composite structural components include channels, $Z$ and $T$ shape stringers, open wall sections, in general and helicopter blades. Local buckling of the flanges near free edges is also a common failure mode in these types of structural components, except helicopter blades. Any free-edge delaminations will lower buckling resistance and, therefore, must be carefully considered in experimental studies. 
CASE 8. Combined Loading

Combined axial tension/compression and in plane shear loading is perhaps the most common loading condition in thin composite structural components. Structural verification tests usually include this type of loading. Again, no free-edge delaminations have been reported in composite structural verification tests from combined loading tension/compression and in plane shear. Similarly, corresponding analytical studies have not been reported either.

The combined loading (axial tension with in-plane shear) induced free edge stresses are computationally simulated using the composite cantilever shown in Fig. 6 . The normalized (with respect to corresponding $\sigma_{x x}$ ) three-dimensional stress field obtained is shown in Fig. 14 for a $[ \pm 10]_{S}$ AS/E APL. The general behavior is similar to that for the axial tension case (Fig. 9) except that the magnitudes of the three interlaminar stresses are about twice those of the axial tension. In either case these are at most about 4 percent of the corresponding axial tension. Since free-edge delaminations in composite structures subjected to combined axial tension and in-plane shear verification tests have not been reported and since the magnitudes of the interlaminar free-edge stresses for this combined loading are about twice those of axial tension, it may be concluded that free-edge delamination occurs only in specially designed laboratory specimens.

CASE 9. Uniform Thermal Load

Composite structures/components are normally subjected to changes in temperatures. Changes in temperatures induce thermal stresses. In addition, composites inherently have initial thermal (residual) stresses which result from the fabrication process. Thermal stresses are generally caused by (1) the difference between cure (about $370^{\circ} \mathrm{F}$ for structural epoxies) and use temperature and (2) the difference between the thermal expansion coefficients 
along the fiber direction (about zero) and transverse to the fiber direction (about 20 parts per million).

Though thermal stresses are known to cause transply cracks in composite laminates, the authors are not aware of any free-edge delaminations caused by thermal stress in either composite laboratory specimens or composite components. Also, the authors are not aware of any analytical studies to predict the temperature/moisture effects on the three-dimensional thermal stress field near free-edges. Prediction of these effects on the three-dimensional thermal stress field near-free edges, therefore was a part of this study.

The three-dimensional thermal stresses are determined by subjecting the Cantilever composite component (Fig. 6) to a $230^{\circ} \mathrm{F}$ uniform temperature which is a reasonable operating temperature for composites made from structural epoxies. The normalized (with respect to corresponding $\sigma_{X X}$ ) three-dimensional thermal stress field obtained near the free-edge is shown in Fig. 15 for a $[ \pm 10]_{S} A S / E$ APL. The thermal interlaminar stresses are restricted to a very small free-edge region compared to those from the mechanical load cases. The magnitude of the free-edge thermal interlaminar stresses is about ten times that of the axial tension. The ply in-plane stresses ( $\sigma_{x x}, \sigma_{y z}$, and $\left.\sigma_{x y}\right)$ also have spikes with substantial magnitudes near the free-edge.

One very interesting result in Fig. 15 is the presence of normal in-plane stresses $\left(\sigma_{x x}\right.$ and $\sigma_{y y}$ ) in the interply layer and the inplane shear stress $\left(\sigma_{x y}\right)$ in the plies, adjacent to this interply layer, throughout the laminate. The normal stress in the interply layer are of considerable magnitude and may initiate transply cracks (micro cracks) under thermal cycling. Also, the in-plane thermal shear stress in the plies will contribute to interply delaminations emanating from the intersection of transply cracks and their adjacent plies. 
The significance of free-edge thermal stress to free-edge delamination

is two parts: (1) temperature increases cause compressive interlaminar stress $\left(\sigma_{Z z}\right)$ and therefore will delay free-edge delamination in combined thermal and axial tension loading conditions; and (2) temperature decreases or residual stresses cause tensile interlaminar stress $\left(\sigma_{z z}\right)$ and therefore will aggravate free-edge delamination. Experimental verification/evaluation of either or both of these parts is not that simple since all the matrix properties depend significantly on (1) use temperature and (2) glass transition temperature.

CASE 10. Uniform Moisture (Hygral) Load

Fiber composites made from polymer-base matrices are known to absorb moisture. Moisture absorption induces hygral stresses in the laminate analogous to thermal stresses. Free-edge delaminations due to moisture have not been reported. Analytical studies to evaluate the three-dimensional hygral stresses near the free-edge have not been reported either. Therefore, the present study included evaluation of the three-dimensional hygral stress field near free-edges.

The free-edge hygral stresses are determined by subjecting the cantilever composite laminate (Fig. 6) to a uniform 1 percent moisture absorption by weight. This moisture is considered to be the amount of moisture polymer-base composites will absorb when exposed to normal service environments. The three-dimensional hygral stress field obtained is shown in Fig. 16 for a $[ \pm 10]_{S} A S / E$ APL. The behavior is similar to the thermal stress field case described in the previous section. The discussion for the thermal stress field applies to the hygral stress field in Fig. 16 as well.

\section{COMPARISONS}

In the previous sections, the three-dimensional stress field near the free-edge for each individual case was compared to the axial tension case. In 
this section we summarize the free-edge interlaminar stresses $\left(\sigma_{z z}\right.$ and $\left.\sigma_{X z}\right)$ for all the cases (Fig. 6) using bar-charts.

The maximum magnitude of interlaminar normal stress $\left(\sigma_{z z}\right)$ is summarized in Fig. 17 for all the cases. The points to be noted in this figure are: (1) Axial tension $\left(\sigma_{x x}\right)$ causes the smallest $\sigma_{z z}$ of all the mechanical load cases studied; (2) Through-the-thickness shear $\left(\sigma_{x z}\right)$ causes the largest $\sigma_{z z}$ followed by twisting $\left(M_{x x}\right)$; and ( 3 ) Both environmental loads (temperature and moisture) cause considerably larger $\sigma_{z z}$ magnitudes compared to mechanical loads. The corresponding summary for the interlaminar shear stress $\left(\sigma_{x z}\right)$ is shown in Fig. 18. The order of the contributions of the various load cases is the same as for $\sigma_{\mathrm{Zz}}$ (Fig. 17).

The maximum magnitudes of both interlaminar stresses $\left(\sigma_{z z}\right.$ and $\left.\sigma_{x z}\right)$ are summarized in Fig. 19 for all mechanical load cases. It is clear from this figure that free-edge interlaminar shear stress $\sigma_{x z}$ is substantially greater (from 20 to 200 percent) than $\sigma_{z z}$ for all cases except for the through-the-thickness laminate shear stress $\left(\sigma_{x z}\right)$ loading condition. The corresponding summary for the environmental loads is shown in Fig. 20. Again, $\sigma_{X z}$ is substantially greater (by more than two times) than $\sigma_{z z}$.

The major conclusion from the comparison summaries is that axial tension causes the smallest magnitude of the free-edge interlaminar stresses of all the mechanical and environmental load conditions studied.

\section{SUMMARY OF RESULTS}

The results of a study to evaluate the laminate width and loading condition effects on free edge delamination stress fields are summarized below under (A) modeling/solution, (B) free-edge stress fields and (C) free-edge delamination. 


\section{A. Modeling/Solution}

(1) Full-3D analysis is needed to adequately describe the free-edge stress field.

(2) A Finite-thickness interply layer must be included in the computational simulation.

(3) The entire specimen geometry must be simulated.

(4) Special free-edge superelement with progressive substructuring is an effective solution method for laminate free-edge problems.

\section{B. Free-Edge Stress Fields}

(1) Ply angle affects the variation of axial stress near the free edge and its peak value. Results of analyses based on constant axial strain across the specimen width may be inaccurate.

(2) Width-to-thickness ( $w / t$ ) ratio affects the interlaminar normal stress $\left(\sigma_{z z}\right)$ as follows: (1) $w / t$ smaller than $2, \sigma_{z z}$ is compressive; (2) $w / t$ about $4, \sigma_{z z}$ peaks (reach its maximum value); and (3) $w / t$ greater than $30, \sigma_{z 2}$ is negligible.

(3) Width-to-thickness ( $w / t$ ) ratio affects the interlaminar shear stress $\left(\sigma_{x z}\right)$ as follows: (1) $w / t$ greater than $2, \sigma_{x z}$ remains approximately constant; and (2) w/t smaller than 2, $\sigma_{X z}$ increases rapidly.

(4) Other loading conditions cause relatively higher-magnitude free-edge interlaminar stresses compared to individual axial stress.

(5) Environmental loads (temperature and moisture) cause: (1) significantly higher normalized interlaminar stresses compared to those due to mechanical loads, (2) negligible in-plane ply stress and (3) high in-plane interply layer stresses. (This latter effect can only be determined by including a finite thickness interply layer in the analysis model.) 
C. Free-Edge Delamination

(1) Edge-delamination is dominated by the interlaminar shear stress $\sigma_{x z}$, though it may be triggered by the interlaminar normal stress $\sigma_{z z}$.

(2) Width-to-thickness $(w / t)$ ratios of about 4 to 8 yield the highest magnitudes for $\sigma_{z z}$. Analytical and/or experimental results obtained using laminates with this range of $w / t$ ratios can not be scaled to actual structural components.

(3) Structural components with $w / t$ ratios greater than 30 (which is generally the case) are not likely to delaminate at or near free-edges.

\section{REFERENCES}

1. Murthy, P.L.N.; and Chamis, C.C.: A Study of Interply Layer Effects on the Free-Edge Stress field of Angleplied Laminates. NASA TM-86924, 1984.

2. Herakovich, C.T., et al.: Free Edge Strain Concentrations in Real Composite Laminates: Experimental Theoretical Correlation. J. Appl. Mech., vol. 52, no. 4, Dec. 1985, pp. 787-793.

3. Howard, W.E.; Gossard, T. Jr.; and Louis, R.N.: Reinforcement of Composite Laminate Free Edges with U-Shaped Caps. AIAA 27 th Structures, Structures Dynamics and Materials Conference, AIAA, New York, 1986, pp. 472-485. (AIAA Paper 86-0972).

4. Lagace, P.A.: Delamination in Composites - Is Toughness the Key? SAMPE J., vol. 22, no. 6, Nov.-Dec. 1986, pp. 53-60, 75.

5. Murthy, P.L.N.; and Chamis, C.C.: Integrated Composite Analyzer (ICAN): Users and Programmers Manual. NASA TP-2515, 1986. 


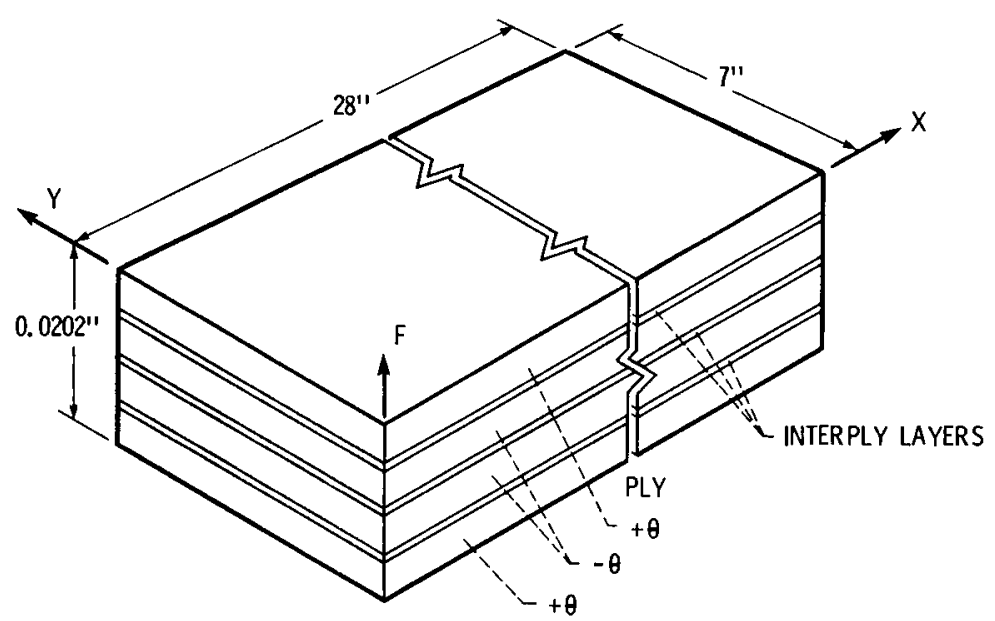

FIGURE 1. - SYMMETRIC ANGLEPLIED LAMINATE OF [ $\pm \theta]$ TYPE WITH INTERPLY LAYERS.

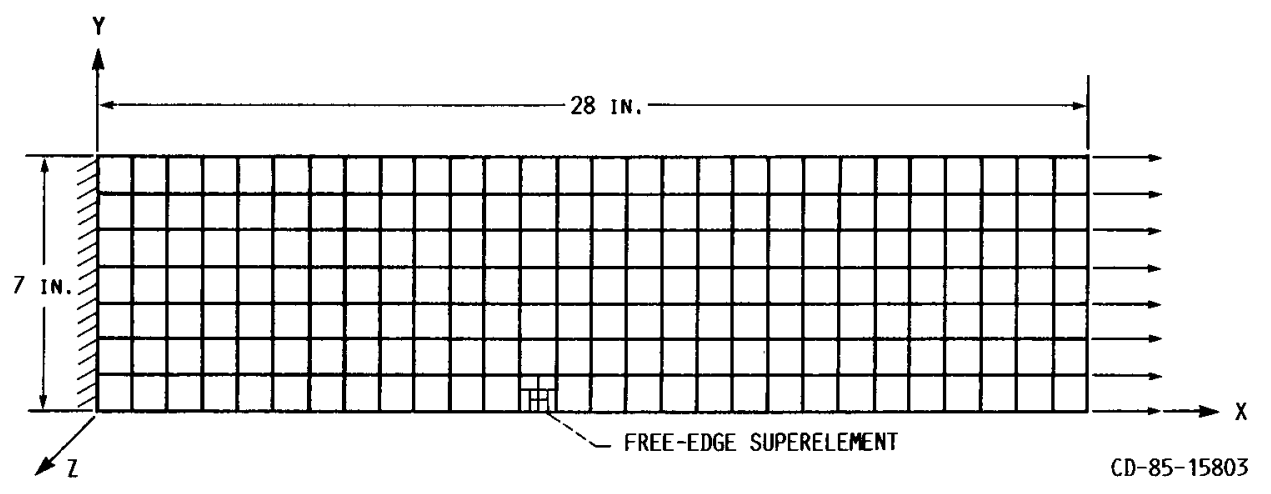

F.E. STATISTICS 1589 20-MODE SOLID F.E.. 224 F.E. IN SUPERELEMENT; 22683 D.0.F.

FIgURE 2. - FINITE ELEMENT MODEL OF ANGLEPLIED LAMINATE UNDER UNIFORM EXTENSIONAL. STRESS.
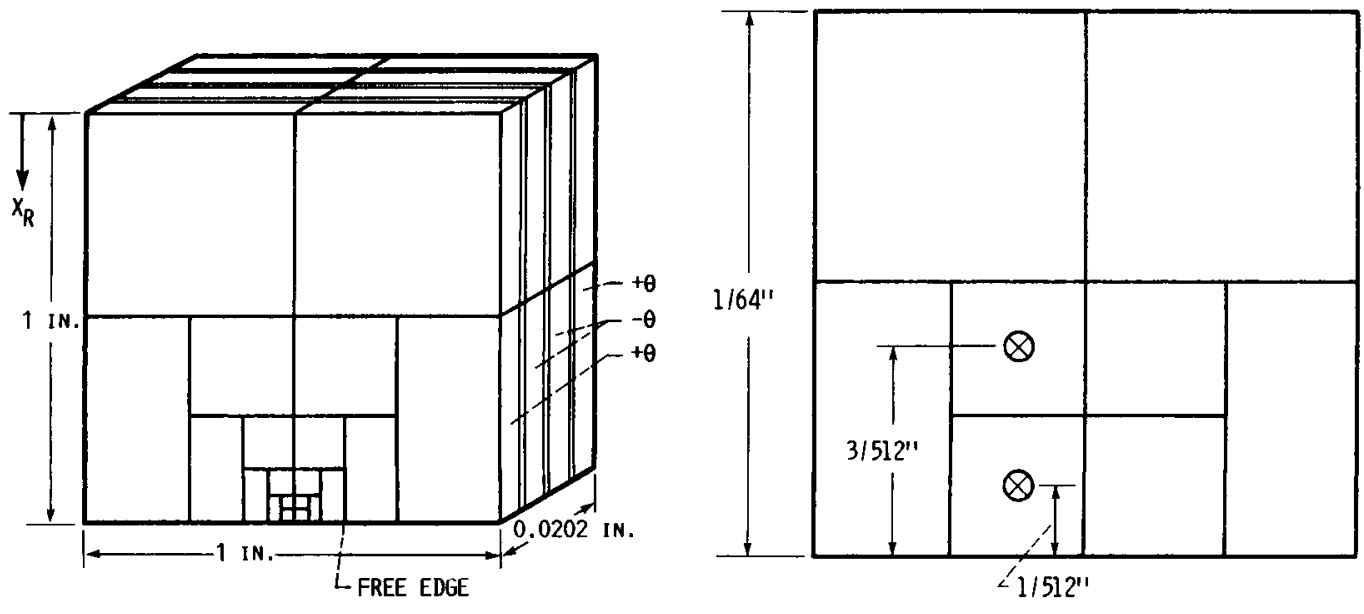

FIGURE 3. - FREE-EDGE REGION OR SUPERELEMENT. (224 F.E.; 2355 D.0.F.) 


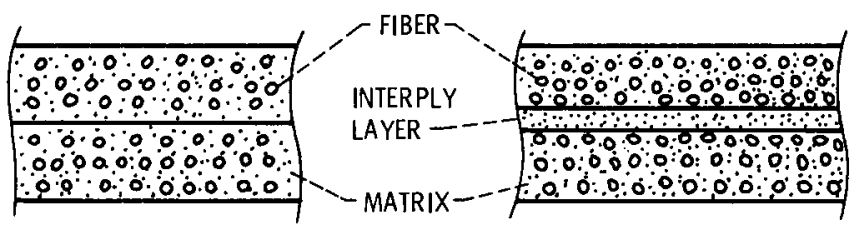

CD - $85-15801$

FIGURE 4. - REPRESENTATION OF LAMINATE WITH INTERPLY LAYER.

$$
\left[\begin{array}{l}
\sigma_{11} \\
\sigma_{22} \\
\sigma_{33} \\
\sigma_{44} \\
\sigma_{55} \\
\sigma_{66}
\end{array}\right]=\left[\begin{array}{llllll}
G_{11} & G_{12} & G_{13} & G_{14} & G_{15} & G_{16} \\
& G_{22} & G_{23} & G_{24} & G_{25} & G_{26} \\
& & G_{33} & G_{34} & G_{35} & G_{36} \\
& & & G_{44} & G_{45} & G_{46} \\
& & & & G_{55} & G_{56} \\
& & & & & G_{66}
\end{array}\right] \times\left[\begin{array}{l}
\varepsilon_{11} \\
\varepsilon_{22} \\
\varepsilon_{33} \\
\varepsilon_{44} \\
\varepsilon_{55} \\
\varepsilon_{66}
\end{array}\right]
$$

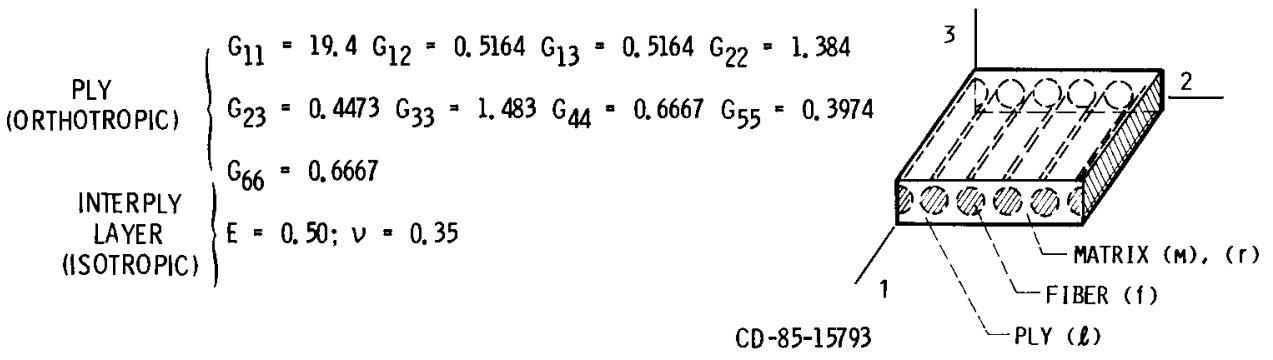

FIGURE 5. - PROPERTIES (MPSI). (AS/EP $0^{\circ}$ PLY AND INTERPLY LAYER.) 
- FREE-EDGE AXIAL STRESS VARIATION VERSUS PLY ANGLE

- WIDTH/THICKNESS RATIO EFFECTS ON FREE-EDGE STRESSES

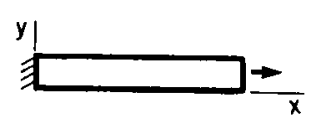

- AXIAL TENSION - REFERENCE

- IN-PLANE SHEAR/BENDING
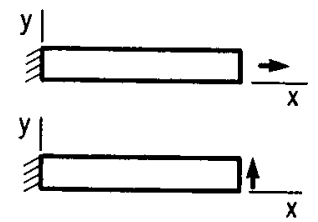

- OUT-OF-PLANE SHEAR/BENDING

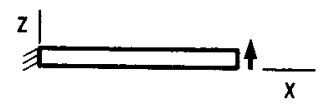

- BENDING MOMENT

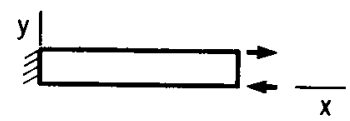

- TWISTING MOMENT

- COMBINED LOADING

(AXIAL TENSION/IN-PLANE SHEAR)

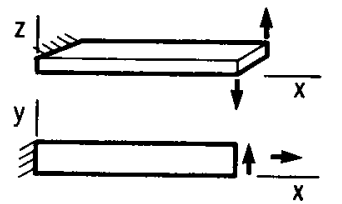

- UNIFORM THERMAL LOAD

- UNIFORM MOISTURE LOAD

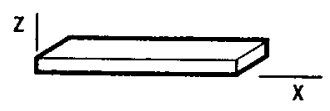

CD-85-15810

FIGURE 6. - LOADING CONDITIONS STUDIED.

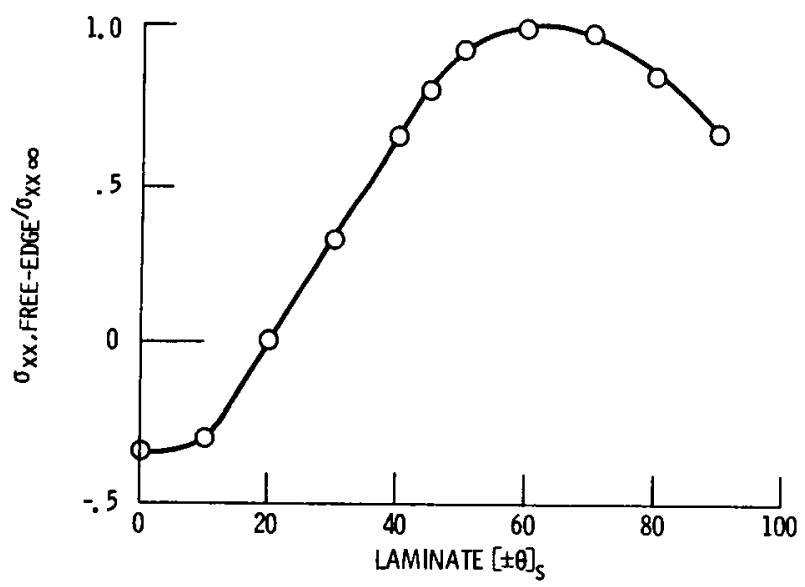

CD-85-15815

FIGURE 7. - VARIATION OF FREE-EDGE AXIAL STRESS RATIO $\left(\sigma_{x x}\right.$, FREE-EDGE $\left./ \sigma_{x X \infty}\right)$ WITH LAMINATE CONFIGURATION $[ \pm \theta]_{s}$. 


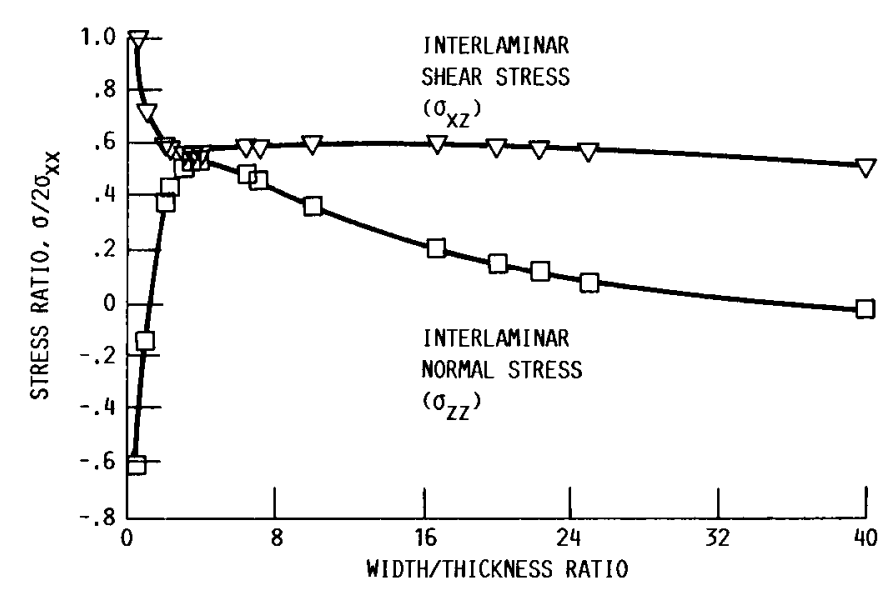

FIGURE 8. - WIDTH-TO-THICKNESS RATIO EFFECTS OF INTERLAMINAR FREE-EDGE STRESSES. ( $\pm 45^{\circ}$ AS/E APL AT 0.55 FVR.)

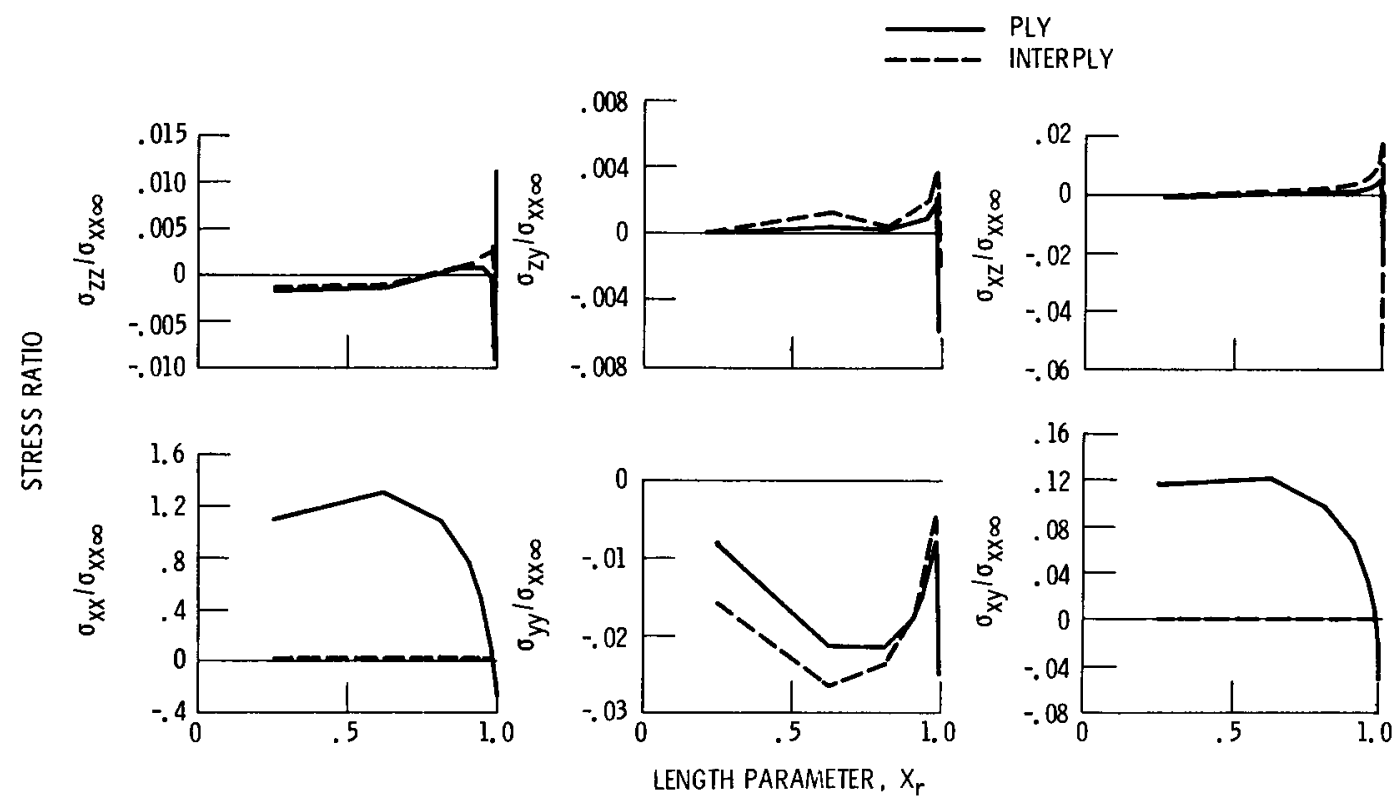

CD-85-15817

FIGURE 9. - FREE-EDGE STRESSES. (AXIAL TENSION; $\pm 10^{\circ}$ AS/E APL AT 0.55 FVR.) 


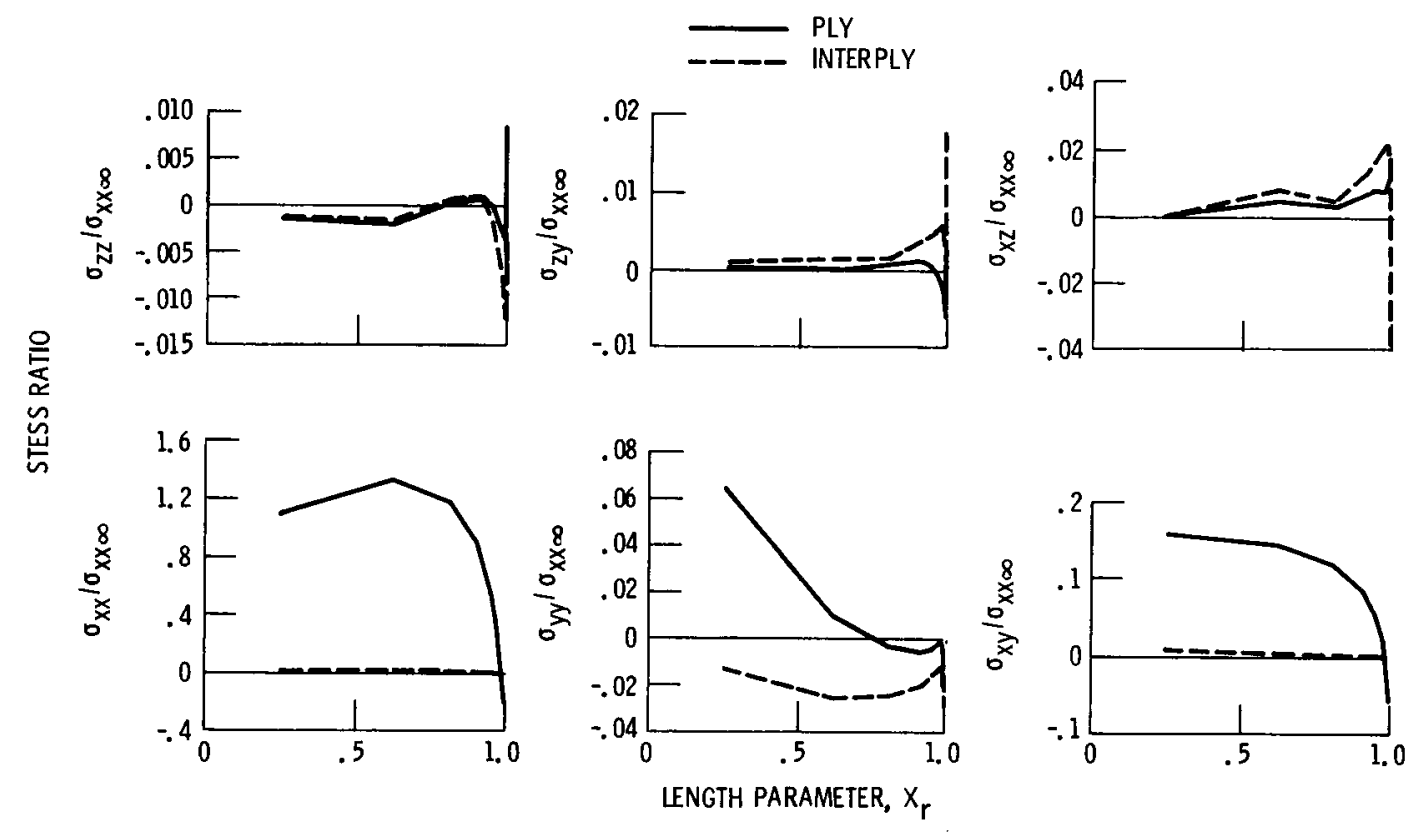

FIGURE 10. - FREE-EDGE STRESSES. (IN-PLANE SHEAR $\left(\sigma_{x y}\right) ; \pm 10^{\circ}$ AS/E APL AT 0.55 FVR.)

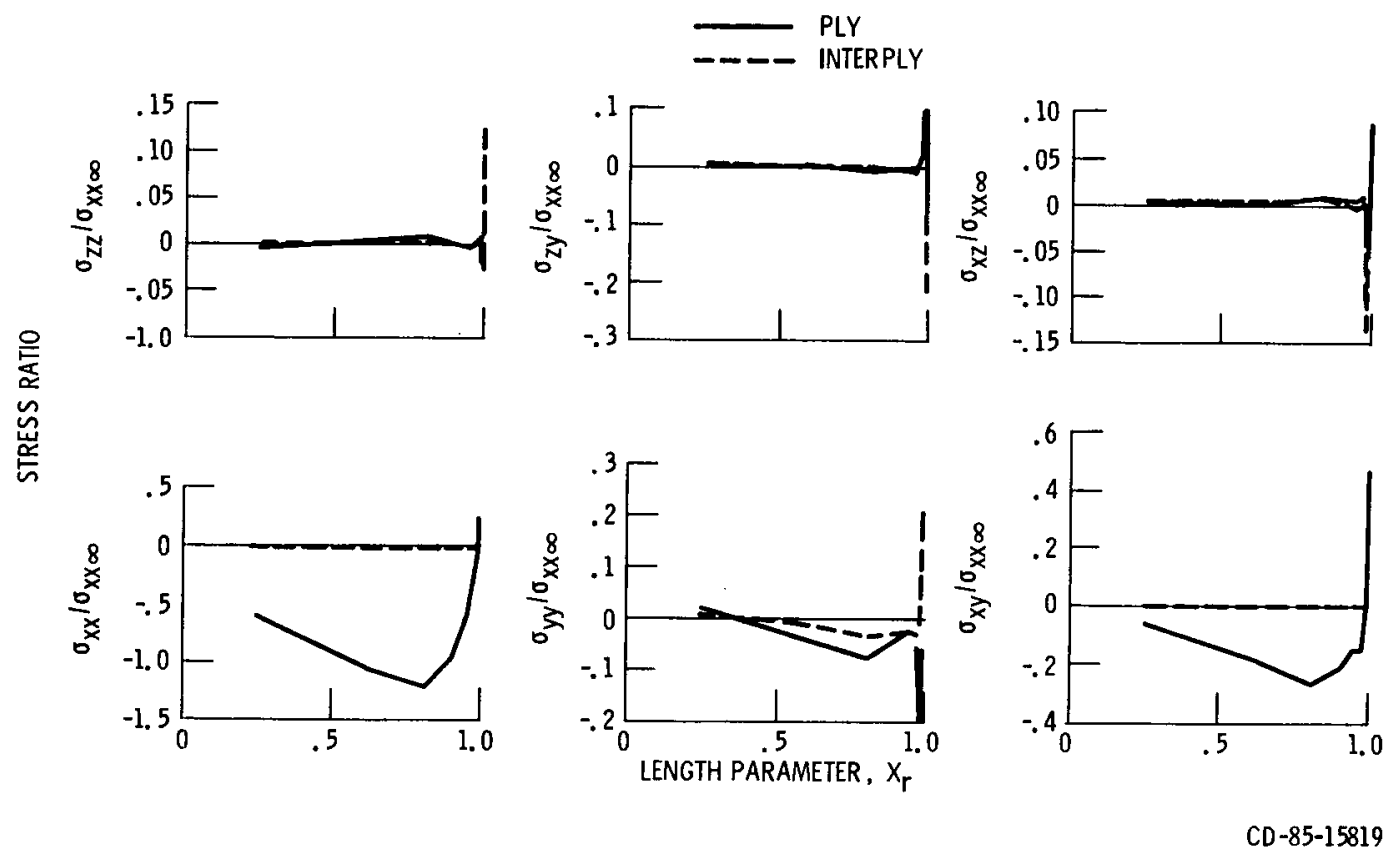

FIGURE 11. - FREE-EDGE STRESSES. (OUT-OF-PLANE SHEAR $\left(\sigma_{\mathrm{xZ}}\right) ; \pm 10^{\circ}$ AS/E APL AT 0.55 FVR.) 


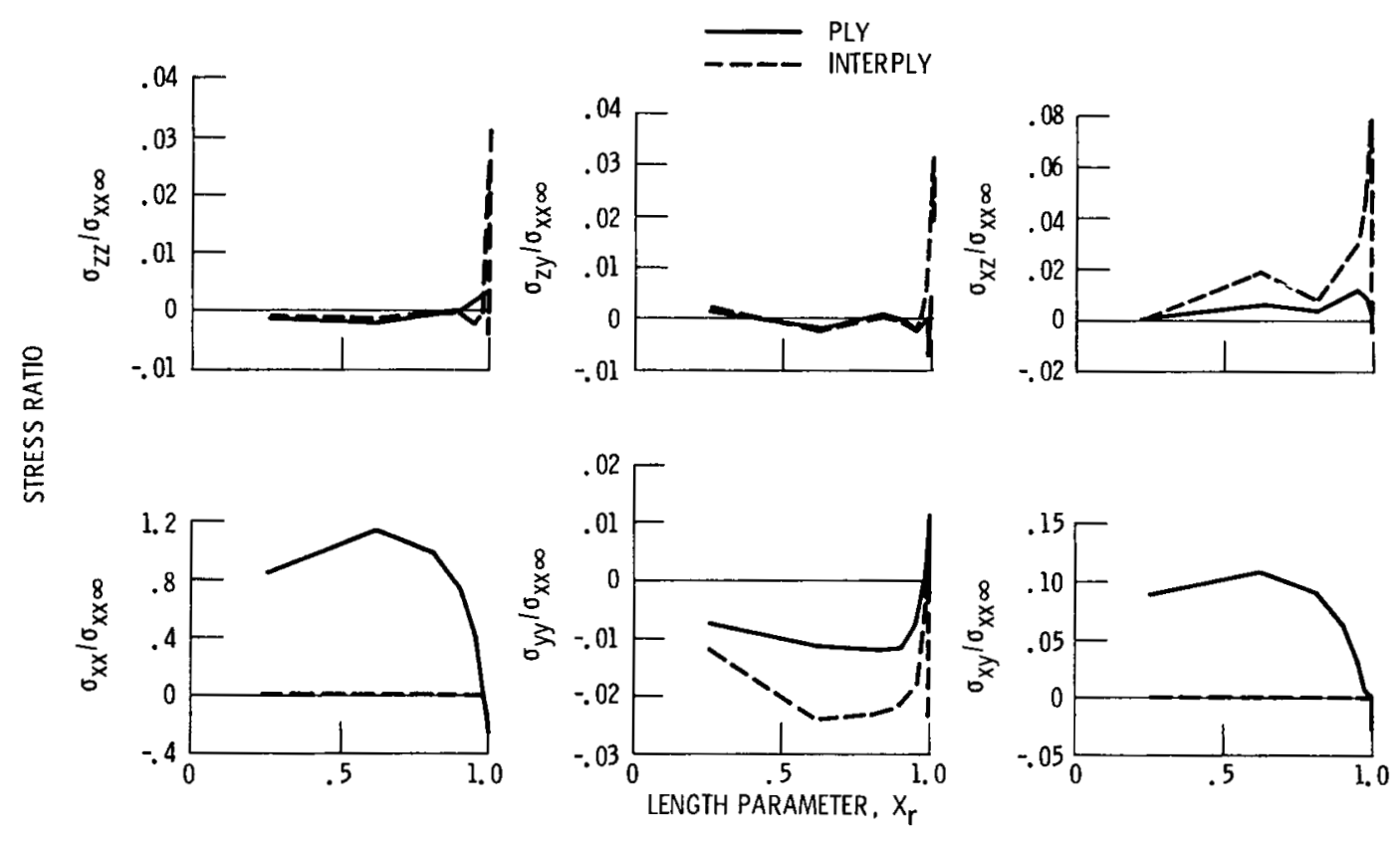

FIgURE 12. - FREE-EDGE STRESSES. (BENDING MOMENT: $\pm 10^{\circ}$ AS/E APL AT 0.55 FVR.)

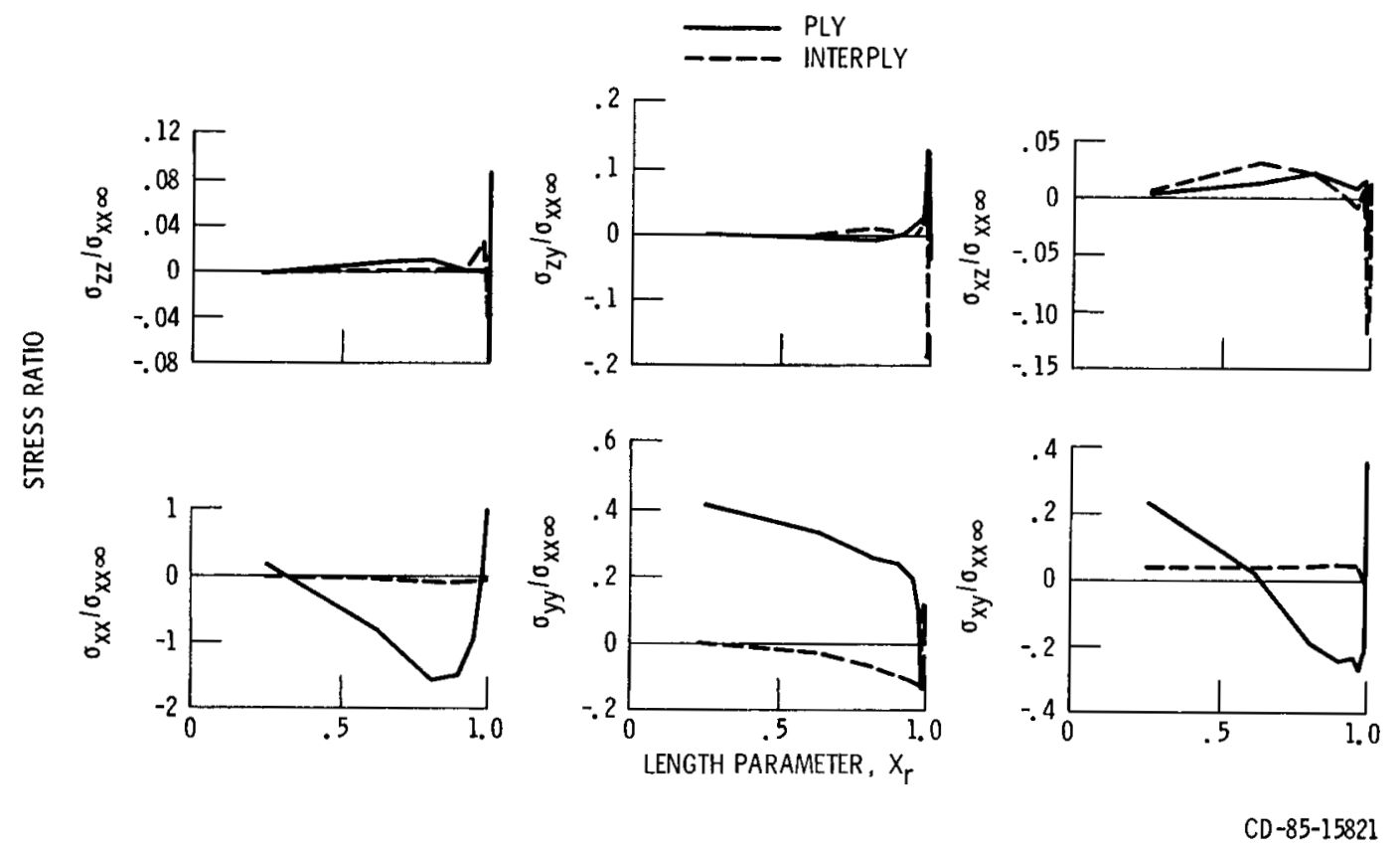

FIGURE 13. - FREE-EDGE STRESSES. (TWISTING MOMENTS: $\pm 10^{\circ}$ AS/E APL AT 0.55 FVR.) 


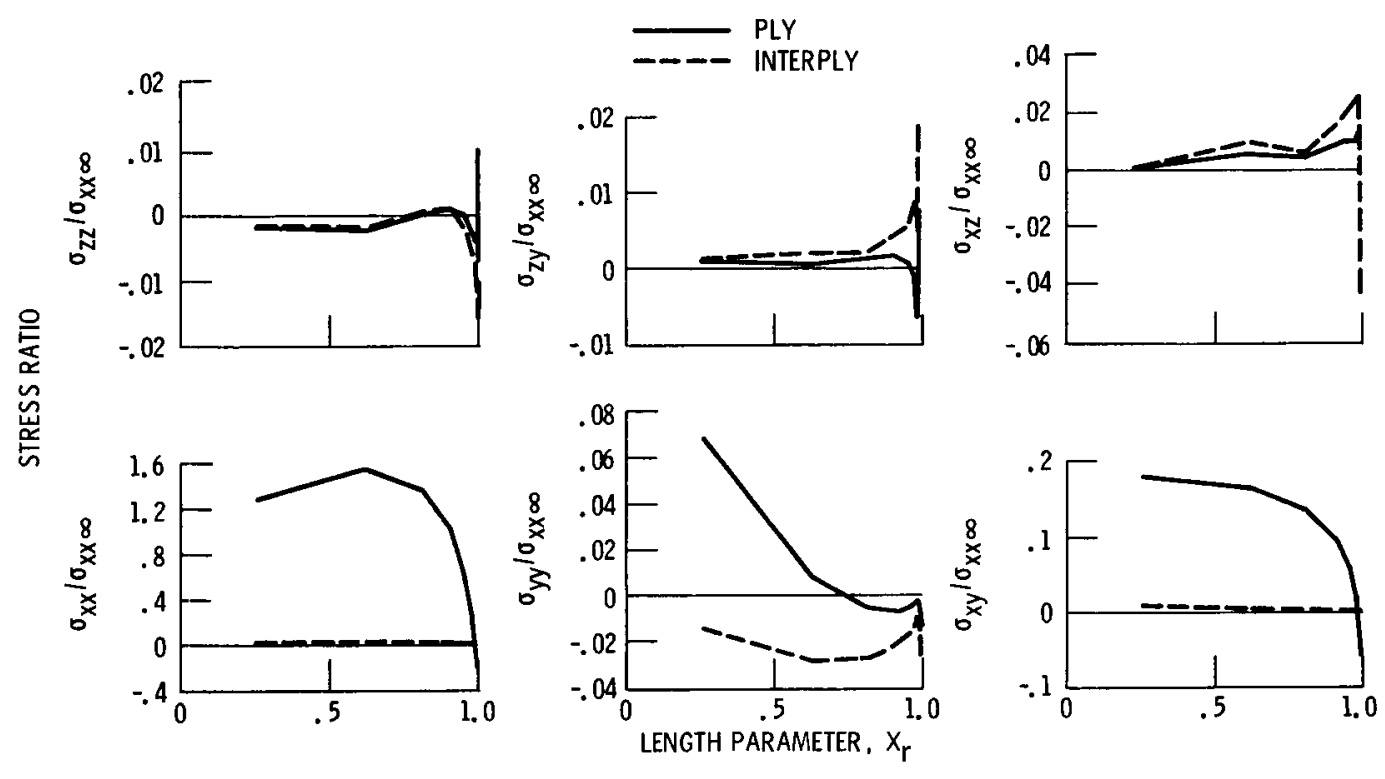

CD-85-15822

FIGURE 14. - FREE-EDGE STRESSES. (COMBINED $\sigma_{x x}$ AND $\sigma_{x y}: \pm 10^{\circ}$ AS/E APL AT 0.55 FVR.)

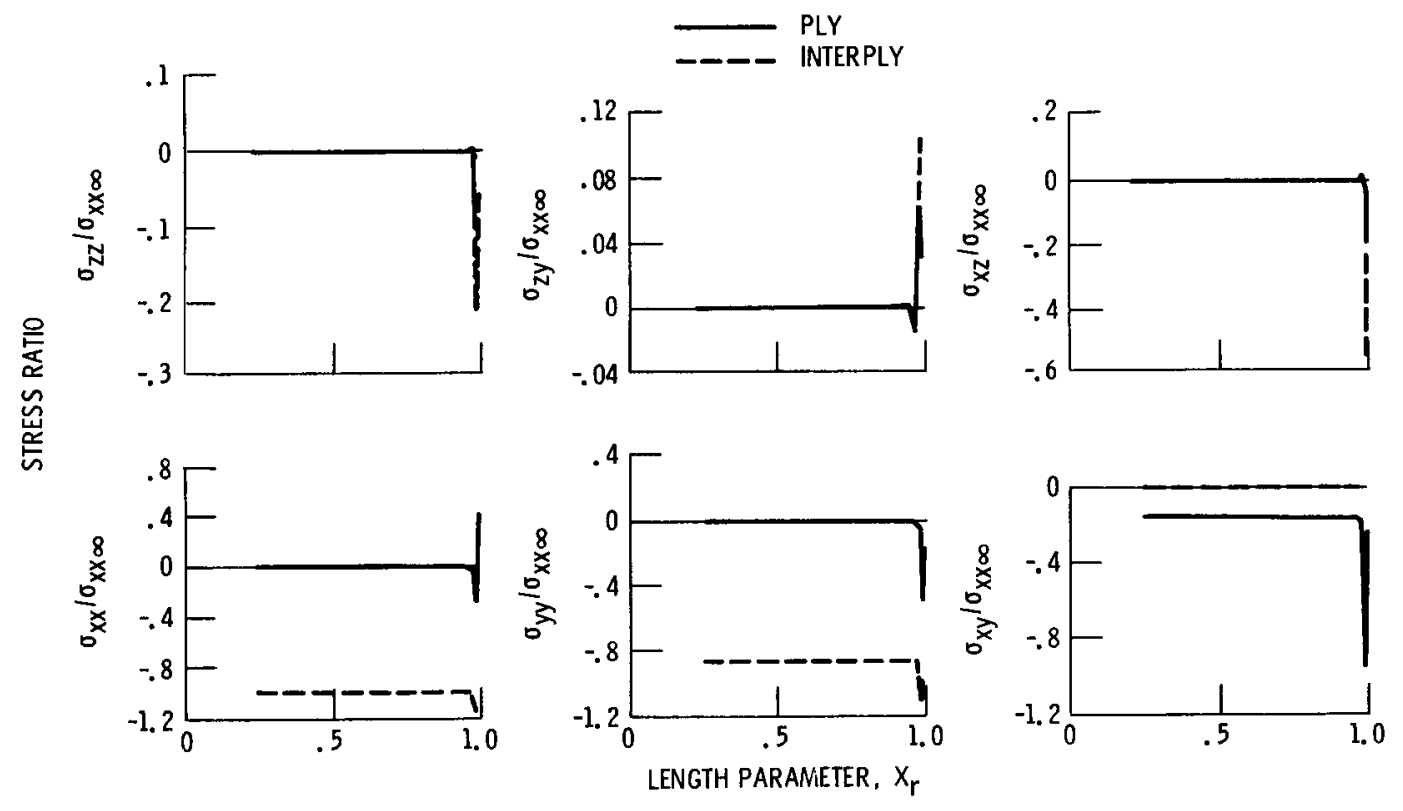

CD-85-15823

FIGURE 15. - FREE-EDGE STRESSES. (230 ${ }^{\circ} \mathrm{F}$ UNIFORM TEMPERATURE: $\pm 10^{\circ}$ AS/E APL AT 0.55 FVR. $)$ 


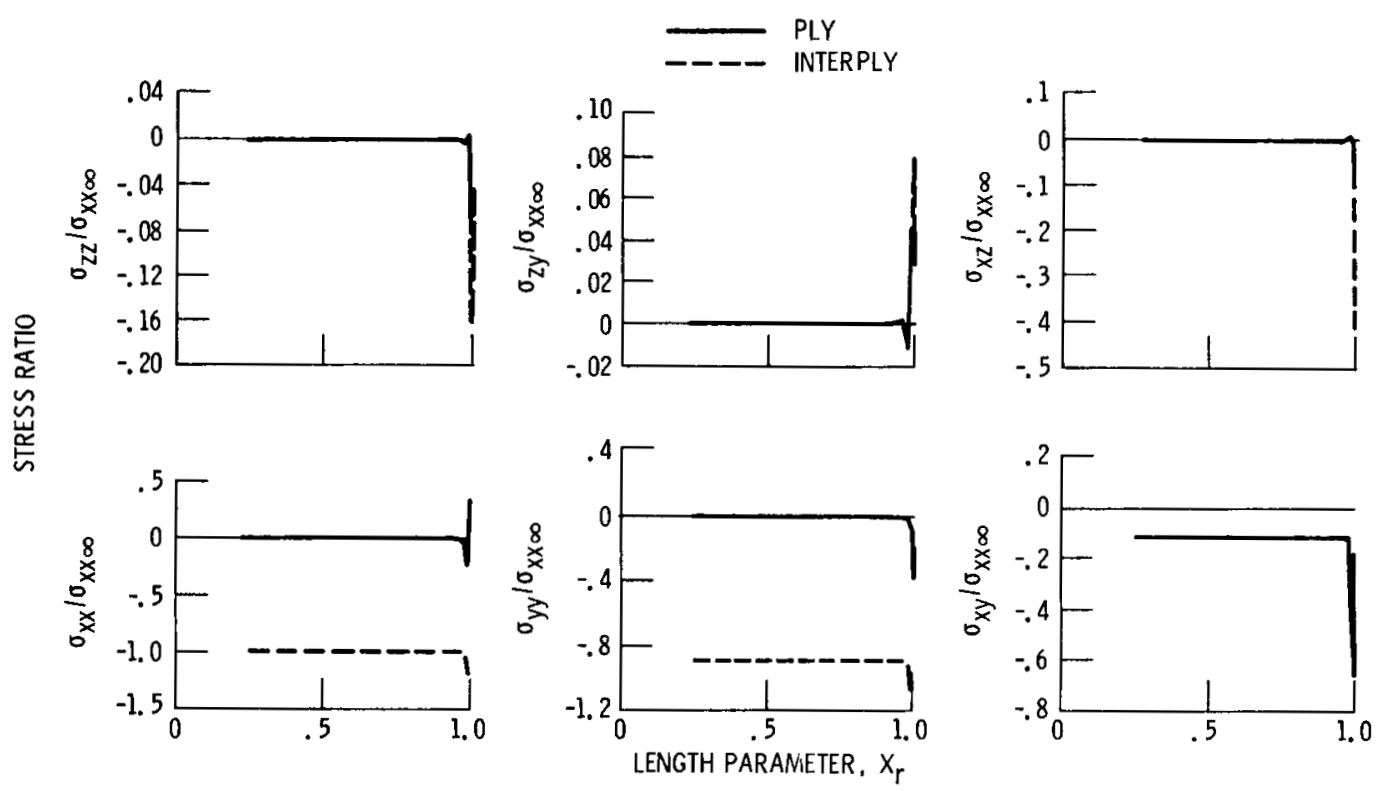

CD-85-15824

FIGURE 16. - FREE-EDGE STRESSES. ( $1 \%$ UNIFORM MOISTURE: $\pm 10^{\circ}$ AS/E APL AT 0.55 FVR.)

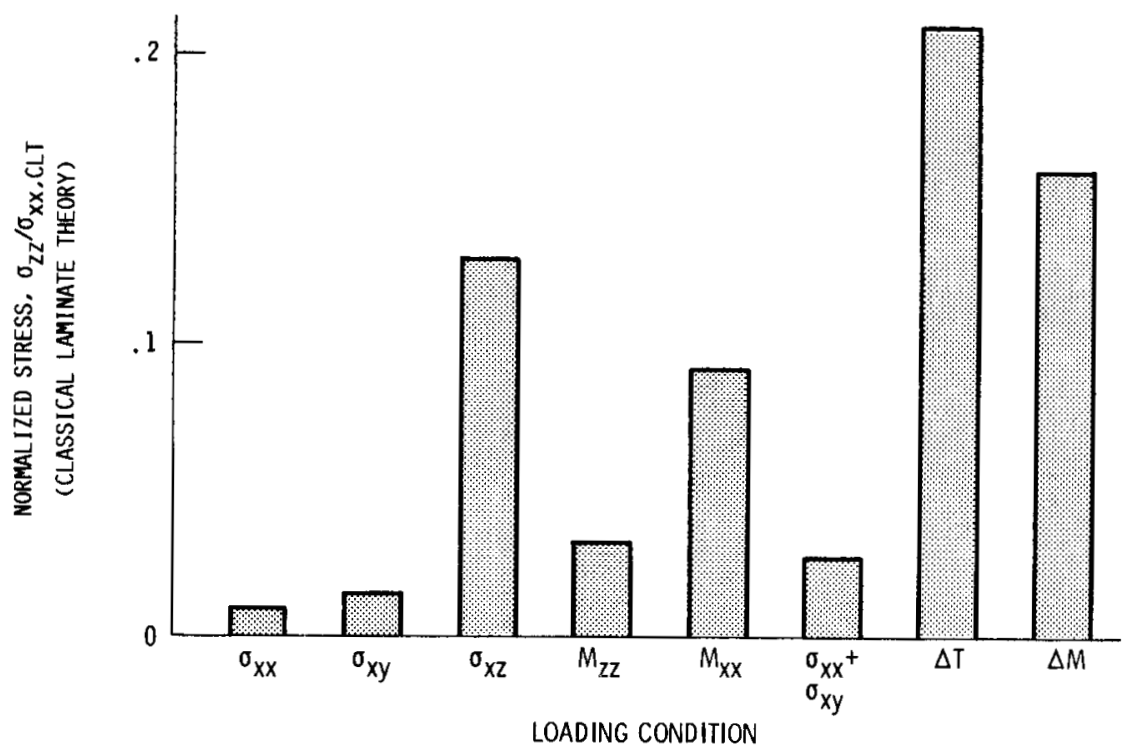

CD-85-15809

FIGURE 17. - FREE-EDGE INTERLAMINAR NORMAL STRESS $\sigma_{z Z} \cdot\left( \pm 10^{\circ}\right.$ AS/E APL AT 0.55 FVR.) 


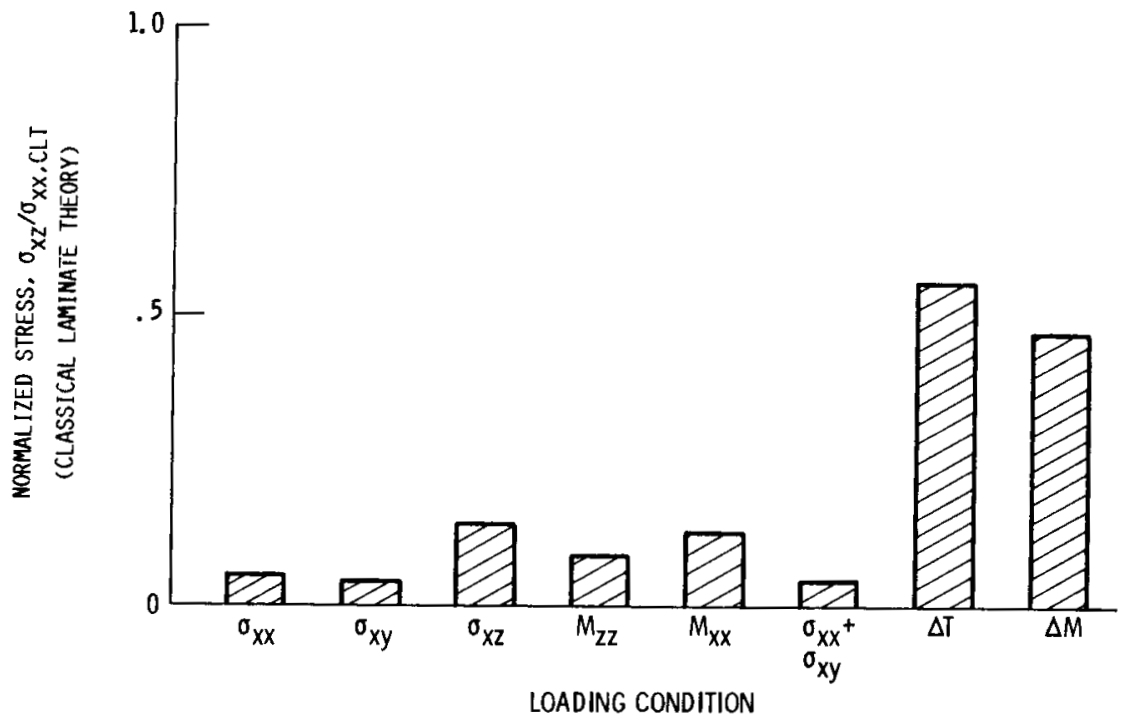

FIGURE 18. - FREE-EDGE INTERLAMINAR SHEAR STRESS $\sigma_{x Z} \cdot\left( \pm 10^{\circ}\right.$ AS/E APL AT 0.55 FVR.)

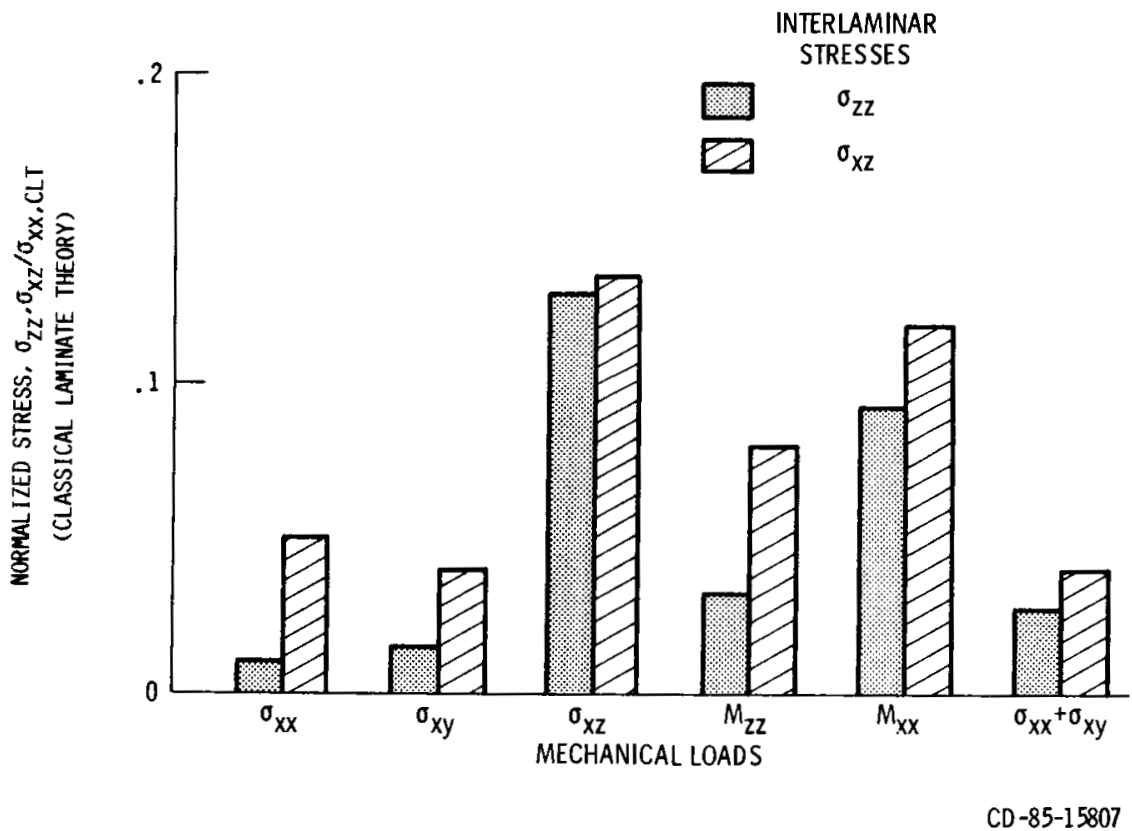

FIGURE 19. - COMPARISON OF FREE-EDGE STRESSES DUE TO MECHANICAL LOADS. $\left( \pm 10^{\circ}\right.$ AS/E APL AT 0.55 FVR.) 


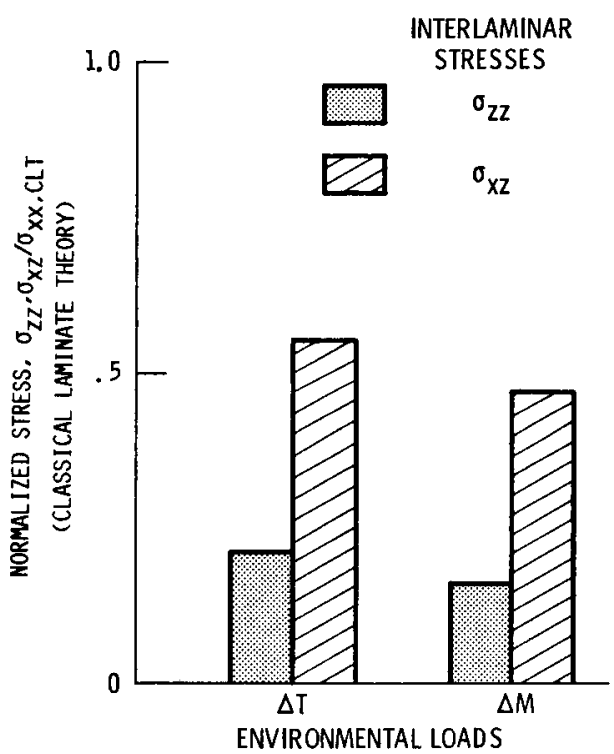

CD-85-15806

FIGURE 20. - COMPARISON OF FREE-EDGE STRESSES DUE TO ENVIRONMENTAL LOADS. ( $\pm 10^{\circ} \mathrm{AS} / \mathrm{E}$ APL AT 0.55 FVR.) 


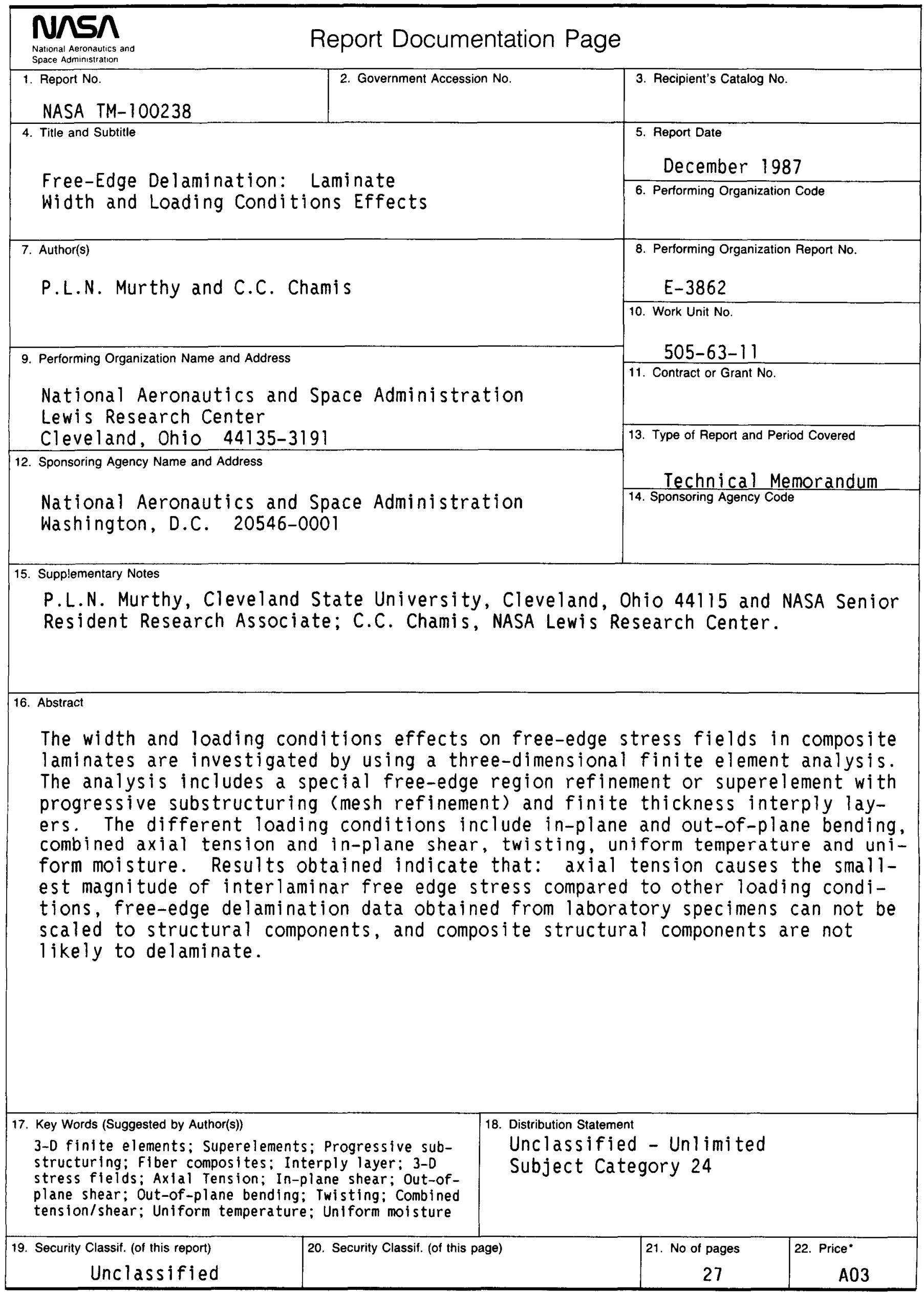

NASA FORM 1626 OCT $86 \quad$ *For sale by the National Technical Information Service, Springfield, Virginia 22161 